\title{
Percurso metodológico para tradução e adaptação de escalas na área de saúde sexual e reprodutiva: uma revisão integrativa
}

\author{
Methodological approach to translation and adaptation of scales \\ in the area of sexual and reproductive health: an integrative review \\ Camiño metodológico para traducción y adaptación de escalas \\ en el área de salud sexual y reproductiva: una revisión integradora
}

\section{Elizian Braga Rodrigues Bernardo', Hellen Lívia Oliveira Catunda', Mirna Fontenele de Oliveira", Paula Renata Amorim Lessa'", Samila Gomes Ribeiro"', Ana Karina Bezerra Pinheiro"v}

\author{
' Universidade Federal do Ceará, Faculdade de Farmácia Odontologia e Enfermagem, \\ Departamento de Enfermagem, Curso de Graduação em Enfermagem (Graduanda). Fortaleza-CE, Brasil. \\ "Universidade Federal do Ceará, Faculdade de Farmácia Odontologia e Enfermagem, \\ Departamento de Enfermagem, Curso de Pós-Graduação em Enfermagem (Doutoranda). Fortaleza-CE, Brasil. \\ I' Universidade Federal do Ceará, Faculdade de Farmácia Odontologia e Enfermagem, \\ Departamento de Enfermagem, Curso de Graduação em Enfermagem (Mestranda). Fortaleza-CE, Brasil. \\ IV Universidade Federal do Ceará, Faculdade de Farmácia Odontologia e Enfermagem, \\ Departamento de Enfermagem, Curso de Graduação em Enfermagem. Fortaleza-CE, Brasil.
}

\section{Submissão: 27-09-2011 Aprovação: 29-04-2013}

\section{RESUMO}

Objetivou-se analisar o percurso metodológico para tradução e adaptação de escalas em dissertações e teses da enfermagem brasileira na área Saúde Sexual e Reprodutiva. Trata-se de uma revisão integrativa de dissertações e teses brasileiras disponíveis no catálogo eletrônico da Associação Brasileira de Enfermagem, no período de 2000 a 2009, sendo identificadas três teses que compuseram os elementos do estudo. As teses analisadas possuíam Beaton et al. como referencial metodológico, no entanto diferenciavam-se quanto ao caminho percorrido nas etapas sugeridas pelos referentes autores. Percebeu-se prevalência da não uniformidade do processo de tradução e adaptação transcultural, bem como o não detalhamento de informações referentes ao percurso metodológico. O estudo possibilitou identificar os principais focos de produção da enfermagem brasileira em recortes de pesquisa do tipo metodológico na área da saúde sexual e reprodutiva, bem como o cumprimento das etapas requeridas para tal. Descritores: Enfermagem; Prática Clínica Baseada em Evidências; Estudos de Validação; Saúde Sexual e Reprodutiva.

\section{ABSTRACT}

The study aimed to analyze the methodological course for translation and adaptation of scales in dissertations and theses of Brazilian nursing in the field of Sexual and Reproductive Health. It is an integrative review of Brazilian dissertations and theses available in the electronic catalog of the Brazilian Nursing Association, in the period from 2000 to 2009, being identified three theses which composed the elements of the study. The three analyzed theses had Beaton et al. as a methodological reference; however, they differ in the followed path as suggested by those authors. It was noticed a prevalence of non-uniformity of the process of translation and transcultural adaptation, as well as no detailed information regarding the methodological course. The study identified the main focus of production of Brazilian nursing on the type of research methodology in the area of sexual and reproductive health, as well as compliance with the steps required to do so.

Key words: Nursing; Evidence-Based Practice; Validation Studies; Sexual and Reproductive Health.

\section{RESUMEN}

El estudio objetivó analisar el percurso metodológico para traducción y adaptación de escalas en disertaciones y tesis de la enfermería brasileña en el ámbito de la Salud Sexual y Reproductiva. Se trata de una revisión integrativa de disertaciones y tesis brasileñas disponibles en el catálogo electrónico de la Associación Brasileña de Enfermería, en el período de 2000 a 2009, en que se identificaron tres tesis que compusieron los elementos del estudio. Las tesis analizadas tenían Beaton et al. como referencial metodológico, pero se diferenciaban en relación al camino recorrido en las fases sugeridas por estes autores. Se percibió prevalencia de la no-uniformidad del proceso de traducción y adaptación cultural, así como no detallamiento de informaciónes sobre el percurso metodológico. El estudio permitió identificar los principales focos de producción de la enfermería brasileña en extractos de investigación del tipo metodológico en el área de la salud sexual y reproductiva, bien como el cumplimiento de las etapas requeridas para ello.

Palabras clave: Enfermería; Práctica Clínica Basada en la Evidencia; Estudios de Validación; Salud Sexual y Reproductiva. 


\section{INTRODUÇÃO}

As mulheres são as principais usuárias do Sistema Único de Saúde (SUS), representando 50,77\% da população brasileira. Dessas, 65\% estão em idade reprodutiva, portanto a atenção à saúde da mulher, principalmente a saúde sexual e reprodutiva, é de suma importância ${ }^{(1)}$. Nesse contexto, a saúde sexual e reprodutiva visa o bem-estar físico, mental e social, primando por uma vida sexual segura e satisfatória à mulher, além de ser um direito e dever do estado construir políticas de saúde que assegurem assistência integral e de qualidade ${ }^{(2)}$.

Assim, é fundamental o compromisso com a implementação de ações de saúde que contribuam para a garantia dos direitos humanos das mulheres e reduzam a morbimortalidade por causas evitáveis, promovendo a integralidade e a promoção da saúde como princípios norteadores, bem como a busca pela consolidação de avanços no campo dos direitos sexuais e reprodutivos ${ }^{(1)}$.

Diante disso, a Enfermagem exerce um papel fundamental no cuidado à mulher, por configurar-se como uma profissão que mantém uma grande proximidade com os clientes nos diversos níveis de atenção. Portanto, são necessárias investigações aprofundadas sobre esse estrato populacional com vistas à viabilização de instrumentos que possibilitem mensurar as necessidades da mulher, especificamente em relação à saúde sexual e reprodutiva, e que sejam capazes de possibilitar inferências de diagnósticos acurados e intervenções eficazes, contribuindo para a melhoria da saúde e qualidade de vida da população feminina ${ }^{(3)}$.

Uma das estratégias utilizadas mundialmente na busca de melhorias na saúde é a utilização de escalas direcionadas para mensuração dos diversos aspectos relacionados aos determinantes das condições de saúde. Todavia, a maioria das escalas é de origem estrangeira sendo imprescindível a tradução e a adaptação de instrumentos previamente validados em outros países, por ser um processo que minimiza custos e facilita o intercâmbio entre os pesquisadores ${ }^{(4)}$.

Logo, para tornar uma escala estrangeira válida e passível de aplicação no contexto brasileiro é preciso seguir algumas etapas, como a tradução para o idioma local, a adaptação transcultural, a aplicação à população alvo e a validação do instrumento. No entanto, a combinação de diversas metodologias em determinados tipos de estudos pode contribuir para a falta de rigor, a inacurácia e o viés, sendo recomendado o seguimento de padrões de rigor metodológico com eficácia comprovada ${ }^{(5)}$.

Diante do exposto, surgiu o questionamento acerca da existência de uma uniformidade nos passos metodológicos utilizados pelos pesquisadores para o processo de tradução e adaptação de escalas.

Reconhecendo a necessidade de seguir um rigor metodológico para um processo exitoso de tradução e adaptação transcultural de escalas, acredita-se que a construção de um panorama das abordagens metodológicas possa propiciar aos enfermeiros e pesquisadores uma relevante fonte de pesquisa capaz de subsidiar escolhas mais acertadas e, consequentemente, melhorar o delineamento de estudos sobre validação de instrumentos de mensuração.
Dispor de instrumentos científicos confiáveis e válidos direcionados para a Saúde Sexual e Reprodutiva feminina é uma contribuição relevante para a prática clínica, viabilizando ações eficazes para a promoção da saúde e da qualidade de vida das mulheres, bem como para a produção científica sobre a temática, favorecendo a discussão acadêmica sobre o tema ${ }^{(6)}$.

Considerando o acima exposto, o objetivo do estudo foi analisar o percurso metodológico para a tradução e adaptação de escalas em dissertações e teses da enfermagem brasileira na área de Saúde Sexual e Reprodutiva.

\section{METODOLOGIA}

Trata-se de uma revisão integrativa das dissertações e teses brasileiras acerca do processo de tradução e adaptação de escalas da área de saúde sexual e reprodutiva. Esse tipo de pesquisa é a mais ampla abordagem metodológica referente às revisões, permitindo a inclusão de estudos experimentais e não experimentais para uma compreensão completa do fenômeno analisado. Combina também dados da literatura teórica e empírica, além de incorporar um vasto leque de propósitos: definição de conceitos, revisão de teorias e evidências, e análise de problemas metodológicos de um tópico particular. A ampla amostra, em conjunto com a multiplicidade de propostas, deve gerar um panorama consistente e compreensível de conceitos complexos, teorias ou problemas de saúde relevantes para a Enfermagem ${ }^{(5)}$.

O referencial teórico adotado para o desenvolvimento deste estudo foi a Prática Baseada em Evidências (PBE). A implementação da PBE na Enfermagem incentiva o enfermeiro a conduzir pesquisas direcionadas para as necessidades da prática clínica e/ou a utilização de resultados de pesquisas disponíveis na literatura ${ }^{(7)}$.

Procedeu-se ao levantamento dos dados no catálogo eletrônico de dissertações e teses da Associação Brasileira de Enfermagem (ABEn) (http://www.abennacional.org.br), uma vez que o seu Centro de Estudos e Pesquisas em Enfermagem (CEPEn), criado em 17 de julho de 1971 e destinado a divulgação da pesquisa em Enfermagem, possui o maior banco de teses e dissertações na área de Enfermagem no Brasil, hoje com mais de 4.000 trabalhos registrados em seu acervo referente às produções de 2000 a 2009, dado que justifica o período analisado.

Para tanto, seguiu-se os passos descritos para o desenvolvimento de uma Revisão Integrativa: identificação do tema; formulação de uma questão norteadora; busca e seleção da literatura; categorização e avaliação dos estudos e apresentação da revisão(8-10).

A verificação dos dados foi subsidiada pela seguinte questão norteadora: Qual o percurso metodológico utilizado para tradução e adaptação de escalas, descrito em dissertações e teses da enfermagem brasileira, na área de Saúde Sexual e Reprodutiva nos últimos dez anos?

O levantamento dos trabalhos, na base de dados selecionada, ocorreu inicialmente mediante a leitura dos títulos e dos resumos das dissertações e teses para posterior seleção 
daqueles que atendiam aos critérios de inclusão: estudos completos disponibilizados eletronicamente e estudos que abordavam a tradução, adaptação e validação de escalas na área da Saúde Sexual e Reprodutiva. De um total de 38 trabalhos que abordavam a tradução e adaptação de escalas em áreas temáticas diversas, três o fizeram na área Saúde Sexual e Reprodutiva.

A análise do material foi realizada em julho de 2011 e constou na leitura de três trabalhos completos subsidiada por um instrumento de coleta de dados com questões previamente elaboradas acerca de: dados de identificação da dissertação/ tese; dados de identificação da escala; e percurso metodológico da tradução e adaptação transcultural da dissertação/tese.

Para a apresentação e análise dos dados referentes ao percurso metodológico da tradução e adaptação transcultural das escalas, utilizou-se como referencial teórico as etapas descritas por Beaton et al. ${ }^{(11)}$, uma vez que todas as produções selecionadas para análise fundamentaram-se nesse autor. Segundo o mesmo, a escala em idioma original deve passar pelas seguintes etapas para ser considerada traduzida e adaptada transculturalmente: tradução inicial; síntese da tradução; tradução de volta à língua de origem (back-translation); revisão por um comitê de juízes; pré-teste da versão final e submissão de todos os relatórios e construtos aos autores da escala para verificação do cumprimento de todas as etapas do processo; e validação do instrumento ${ }^{(11)}$.

\section{RESULTADOS}

Na busca pelos estudos de tradução e adaptação de escalas, desenvolvidos nos cursos de mestrado e doutorado brasileiros em Enfermagem, que abordassem a área de Saúde Sexual e Reprodutiva, foram selecionados um número de três trabalhos durante o período de 2000 a 2009, todos eles teses de doutorado.

As Tabelas 1, 2 e 3 mostram os dados extraídos das três teses analisadas. Esses dados permitem observar as variações das metodologias adotadas na tradução e adaptação transcultural de instrumentos de origem estrangeira para serem utilizadas no contexto brasileiro. A Tabela 1 apresenta os dados de identificação das teses: autor, título, ano, origem e direcionalidade temática.

Tabela 1 - Dados de identificação das teses presentes no banco de dados. CEPEN, abr-mai 2011

\begin{tabular}{|c|c|c|c|c|}
\hline Autor & Título & Ano & Origem & Direcionalidade temática \\
\hline Anne Marie Weissheimer & $\begin{array}{c}\text { Tradução, adaptação transcultural } \\
\text { e validação para uso no Brasil do } \\
\text { instrumento Prenatal Psychosocial Profile } \\
\text { (PPP) }\left(\mathrm{T}_{1}\right)\end{array}$ & 2007 & $\begin{array}{l}\text { Universidade de São Paulo. } \\
\text { Escola de Enfermagem de } \\
\text { Ribeirão Preto }\end{array}$ & Assistência pré-natal \\
\hline $\begin{array}{c}\text { Mônica Oliveira Batista } \\
\text { Oriá }\end{array}$ & $\begin{array}{c}\text { Tradução, adaptação e validação da } \\
\text { Breastfeeding Self-Efficacy Scale (BSES): } \\
\text { Aplicação em gestantes }\left(\mathrm{T}_{2}\right)\end{array}$ & 2008 & $\begin{array}{l}\text { Universidade Federal } \\
\text { do Ceará/Faculdade de } \\
\text { Farmácia, Odontologia e } \\
\text { Enfermagem }\end{array}$ & Aleitamento materno \\
\hline $\begin{array}{c}\text { Teresa Cristina Martins } \\
\text { Leite Imada }\end{array}$ & $\begin{array}{l}\text { Adaptação transcultural e validação da } \\
\text { Family Dynamics Measure II (FDM II) } \\
\text { para familiares de mulheres portadoras de } \\
\text { câncer de mama no Brasil }\left(\mathrm{T}_{3}\right)\end{array}$ & 2008 & $\begin{array}{l}\text { Universidade de São Paulo/ } \\
\text { Escola de Enfermagem de } \\
\text { Ribeirão Preto }\end{array}$ & $\begin{array}{l}\text { Dinâmica familiar de } \\
\text { mulheres com câncer de } \\
\text { mama }\end{array}$ \\
\hline
\end{tabular}

Tabela 2 - Dados de identificação das escalas adaptadas transculturalmente nas teses presentes no banco de dados. CEPEN, abr-mai 2011.

\begin{tabular}{|c|c|c|c|c|c|c|}
\hline Tese & Título da escala & $\begin{array}{l}\text { Idioma } \\
\text { e país de } \\
\text { origem da } \\
\text { escala }\end{array}$ & $\begin{array}{c}\text { Ano de } \\
\text { publicação } \\
\text { da escala } \\
\text { original }\end{array}$ & Objetivo da escala & $\begin{array}{c}\text { Itens } \\
\text { da } \\
\text { escala }\end{array}$ & $\begin{array}{l}\text { Tradução e adaptação } \\
\text { em outros países }\end{array}$ \\
\hline $\mathrm{T}_{1}$ & $\begin{array}{c}\text { Prenatal Psychosocial } \\
\text { Profile (PPP) }\end{array}$ & $\begin{array}{l}\text { Inglês, } \\
\text { Estados } \\
\text { Unidos }\end{array}$ & 1994 & $\begin{array}{l}\text { Medir as percepções da mulher sobre } \\
\text { estresse, apoio do companheiro, apoio de } \\
\text { outros e auto-estima durante a gestação. }\end{array}$ & 44 & Não informa \\
\hline $\mathrm{T}_{2}$ & $\begin{array}{c}\text { Breastfeeding } \\
\text { Self-Efficacy Scale } \\
\text { (BSES) }\end{array}$ & $\begin{array}{l}\text { Inglês, } \\
\text { Canadá }\end{array}$ & 1999 & $\begin{array}{l}\text { Medir a auto-eficácia das mães na } \\
\text { habilidade em amamentar. }\end{array}$ & 33 & $\begin{array}{c}\text { Processo já concluído na } \\
\text { Austrália } \\
\text { Porto Rico } \\
\text { China } \\
\text { Polônia }\end{array}$ \\
\hline $\mathrm{T}_{3}$ & $\begin{array}{l}\text { Family Dynamics } \\
\text { Measure II (FDM II) }\end{array}$ & $\begin{array}{l}\text { Inglês, } \\
\text { Estados } \\
\text { Unidos }\end{array}$ & 1993 & $\begin{array}{c}\text { Avaliar a dinâmica familiar em situação } \\
\text { de saúde e doença, para o uso clínico } \\
\text { e da pesquisa, capaz de identificar } \\
\text { famílias em risco. }\end{array}$ & 66 & $\begin{array}{l}\text { Processo em andamento } \\
\text { na Turquia e Grécia }\end{array}$ \\
\hline
\end{tabular}


Tabela 3 - Dados do percurso metodológico das teses presentes no banco de dados. CEPEN, abr-mai 2011.

\begin{tabular}{|c|c|c|c|c|c|c|c|}
\hline Tese & $\begin{array}{c}\text { Referencial } \\
\text { Metodológico }\end{array}$ & Tradução inicial & $\begin{array}{l}\text { Síntese da } \\
\text { tradução }\end{array}$ & Retro-tradução & $\begin{array}{l}\text { Comitê de } \\
\text { juízes }\end{array}$ & Pré-teste & $\begin{array}{l}\text { Submissão } \\
\text { aos autores da } \\
\text { escala }\end{array}$ \\
\hline $\mathrm{T}_{1}$ & $\begin{array}{c}\text { Beaton et al. } \\
2000\end{array}$ & $\begin{array}{l}\text { Três tradutores } \\
\text { independentes: } \\
\text { a pesquisadora e } \\
\text { dois profissionais } \\
\text { da saúde. Não } \\
\text { há clareza se } \\
\text { os objetivos da } \\
\text { tradução foram } \\
\text { revelados para os } \\
\text { tradutores. }\end{array}$ & $\begin{array}{l}\text { Síntese } \\
\text { realizada por } \\
\text { três tradutores. }\end{array}$ & $\begin{array}{c}\text { Dois tradutores } \\
\text { da área de letras, } \\
\text { tendo como } \\
\text { língua materna } \\
\text { o português } \\
\text { e fluência no } \\
\text { inglês. }\end{array}$ & $\begin{array}{c}\text { Formado por } \\
\text { três enfermeiras } \\
\text { obstétricas e a } \\
\text { pesquisadora. }\end{array}$ & $\begin{array}{c}\text { Aplicado } \\
\text { com uma } \\
\text { amostra de } \\
39 \text { gestantes. }\end{array}$ & $\begin{array}{l}\text { Não mencionou } \\
\text { esta etapa. }\end{array}$ \\
\hline $\mathrm{T}_{2}$ & $\begin{array}{c}\text { Beaton et al. } \\
2000\end{array}$ & $\begin{array}{c}\text { Dois tradutores } \\
\text { idenpendentes: } \\
\text { somente um da } \\
\text { área da saúde. } \\
\text { Os objetivos da } \\
\text { tradução foram } \\
\text { revelados apenas } \\
\text { para o tradutor que } \\
\text { não era profissional } \\
\text { da saúde. }\end{array}$ & $\begin{array}{l}\text { Etapa } \\
\text { realizada, } \\
\text { mas não há } \\
\text { clareza quem } \\
\text { participou da } \\
\text { construção da } \\
\text { síntese. }\end{array}$ & $\begin{array}{l}\text { Dois tradutores } \\
\text { estudantes de } \\
\text { medicina, tendo } \\
\text { como língua } \\
\text { materna o inglês } \\
\text { e fluência no } \\
\text { português. }\end{array}$ & $\begin{array}{l}\text { Formado por } \\
\text { três professores } \\
\text { universitários } \\
\text { doutores. }\end{array}$ & $\begin{array}{l}\text { Aplicado com } \\
\text { uma amostra } \\
\text { de } 30 \\
\text { mulheres ( } 15 \\
\text { gestante e } 11 \\
\text { puérperas). }\end{array}$ & $\begin{array}{c}\text { Não mencionou } \\
\text { essa etapa. }\end{array}$ \\
\hline $\mathrm{T}_{3}$ & $\begin{array}{c}\text { Beaton et al. } \\
2000 \\
\text { Chalow, } 1995 \\
\text { Maneesriwongul, } \\
\text { Dixon, } 2004 .\end{array}$ & $\begin{array}{l}\text { Três tradutores } \\
\text { independentes, } \\
\text { sendo dois da } \\
\text { área da saúde. } \\
\text { Não há clareza } \\
\text { se os objetivos da } \\
\text { tradução foram } \\
\text { revelados para os } \\
\text { tradutores. }\end{array}$ & $\begin{array}{l}\text { Etapa realizada. } \\
\text { Refere que foi } \\
\text { construída por } \\
\text { uma equipe de } \\
\text { pesquisadores, } \\
\text { incluindo a } \\
\text { autora. Não } \\
\text { especifica } \\
\text { quem são } \\
\text { os outros } \\
\text { participantes. }\end{array}$ & $\begin{array}{c}\text { Dois tradutores, } \\
\text { sendo um deles } \\
\text { bilíngüe com } \\
\text { nacionalidade } \\
\text { inglesa e } \\
\text { pesquisador na } \\
\text { área de saúde } \\
\text { mental. }\end{array}$ & $\begin{array}{c}\text { Dois } \\
\text { profissionais } \\
\text { de saúde que } \\
\text { possuíam } \\
\text { experiência } \\
\text { com família. }\end{array}$ & $\begin{array}{l}\text { Não realizou } \\
\text { essa etapa. }\end{array}$ & Realizou. \\
\hline
\end{tabular}

No que se refere aos dados de identificação das teses, elencados na Tabela 1, todos os autores especificaram no título se tratar de um estudo de tradução, adaptação e validação de escala.

Ao analisarmos a origem das produções, verificou-se que duas foram desenvolvidos na região Sudeste e a outra na Região Nordeste. As teses produzidas na Região Sudeste, foram oriundas da Universidade de São Paulo (USP) de Ribeirão Preto. Já a produção referente à Região Nordeste adveio da Universidade Federal do Ceará (UFC).

Em relação à direcionalidade temática, uma enfocou a assistência pré-natal, uma o aleitamento materno e outra a dinâmica familiar de mulheres com câncer de mama.

Na Tabela 2, foram identificados o título da escala, a origem, ano de publicação da escala original, objetivo da escala, quantidade de itens da escala original e países que já realizaram a tradução e a adaptação transcultural da escala em estudo.

Conforme a Tabela 2, os títulos das escalas originais que foram objetos de estudo das teses analisadas foram: Prenatal Psychosocial Profile (PPP), Breastfeeding Self-Efficacy Scale (BSES), Family Dynamics Measure II (FDM II). Ao analisar o país de origem da escala, percebe-se que todas foram desenvolvidas no Continente Norte Americano e na década de 90.
Os objetivos das escalas em análise foram divididos em três direcionalidades temáticas: 1. Assistência pré-natal (mensurar as percepções da mulher sobre o estresse, sobre o apoio do companheiro, o apoio dos outros e a autoestima durante a gestação); 2. Amamentação (mensurar a autoeficácia das mães na habilidade em amamentar); e 3. Dinâmica familiar (avaliar a dinâmica familiar em situação de saúde e doença, para o uso clínico e de pesquisa, capaz de identificar famílias em risco).

Quanto aos itens das escalas, observamos uma variação mínima de 33 itens e máxima de 66 itens, com média de 49,5 itens.

De acordo, ainda, com a Tabela 2, percebe-se que, em uma das teses analisadas (T1), o autor não informou se o instrumento de medida havia sido traduzido e adaptado transculturalmente para outros idiomas, diferente do que se constatou nas outras duas teses (T2 e T3), quando as autoras esclarecem que, além da versão adaptada para o Brasil, existiam as versões produzidas por autores na Austrália, Porto Rico, China e Polônia para T2 e por autores na Turquia e Grécia para T3.

Na Tabela 3, estão presentes os dados referentes ao percurso metodológico adotado pelos pesquisadores em estudo, segundo as etapas estabelecidas pelo referencial teórico comum às três teses: Beaton et al. ${ }^{(11)}$. 
Conforme observado, as três teses adotaram o mesmo referencial metodológico: Beaton et al. ${ }^{(11)}$. Entretanto, em uma delas (T3), houve a associação de mais dois referenciais teóricos: Chalow (1995) e Maneesriwongul \& Dixon (2004).

Quanto às etapas do percurso metodológico, os dados coletados foram divididos em subcategorias, segundo as etapas descritas pelo autor adotado: tradução inicial, síntese das traduções, retro-tradução, comitê de juízes, pré-teste e submissão aos autores da escala.

Na primeira etapa, denominada de tradução inicial, constatou-se a participação de pelo menos dois tradutores independentes, com fluência no idioma original (inglês) e alvo (português). No entanto, em dois trabalhos (T1 e T3), esta etapa contou com a participação de mais um tradutor, totalizando três em cada.

Ainda nessa etapa, em T1 os três tradutores envolvidos eram da área da saúde, não ficando explicitado se os mesmos foram informados dos objetivos da tradução. Em T2, somente um dos tradutores era da área da saúde e os objetivos da tradução da escala foram revelados para o outro tradutor. Em T3, dois dos tradutores eram da área da saúde e não ficou claro se eles foram informados dos objetivos da tradução da escala.

$\mathrm{Na}$ segunda etapa, denominada de síntese da tradução, constatou-se que em todas as teses houve a produção de uma síntese das traduções elaboradas na etapa anterior.

Na terceira etapa, denominada de retro-tradução, houve a participação de dois retrotradutores em todas as teses, com semelhança na fluência nos dois idiomas de interesse - português e inglês, mas com variações quanto à especialidade destes: em T1 ambos eram da área de letras, em T2 ambos eram estudantes de medicina e em T3 um era profissional da saúde mental e o outro não teve sua especialidade revelada.

A quarta etapa, denominada de comitê de juízes, foi cumprida por todas as teses, porém com algumas variações: em T1 o comitê contou com a participação de três enfermeiras obstétricas e a autora da tese; em T2 o comitê foi formado por três professores universitários da área, com título de doutor; em T3 o comitê foi composto por dois profissionais da saúde com experiência no contexto da família.

Na quinta etapa, denominada de pré-teste, observou-se que a maioria das teses (T1 e T2) submeteu a versão traduzida e aprovada pelo comitê de juízes a uma parcela da população-alvo, tendo essa amostra variando entre 30 e 39 sujeitos, como sugerido por Beaton e seus colaboradores. Uma autora (T3) não executou essa etapa.

Na sexta etapa, denominada de submissão aos autores da escala, houve cumprimento de apenas uma tese (T3).

\section{DISCUSSÃO}

Buscou-se fundamentar a discussão na síntese do conhecimento evidenciado nas teses analisadas e em outras publicações científicas sobre a temática, a fim de contribuir para uma maior compreensão das etapas metodológicas requeridas para o processo de tradução e adaptação transcultural de instrumentos de mensuração.
O processo de construção do conhecimento reflete as transformações do movimento histórico vivenciado pela enfermagem. Neste movimento dinâmico que visa um avanço criador na práxis do ensino, pesquisa e assistência, os enfermeiros vêm buscando utilizar diferentes e inovadores tipos de estudo ${ }^{(12)}$.

Considerando a relevância dos estudos metodológicos, uma vez que eles disponibilizam instrumentos confiáveis e válidos de mensuração, especialmente na área de saúde sexual e reprodutiva, é fundamental a divulgação desse tipo de produção, como incentivo a futuras pesquisas de convergência metodológica. Portanto, uma das estratégias para o alcance dessa meta seria citar o tipo de estudo ou o seu propósito em seções comuns de busca, como no título do trabalho, a exemplo do que observamos nas teses analizadas.

Constatou-se que no ano de 2008 houve um predomínio da produção científica brasileira acerca do uso de escalas, mais de uma década depois da mesma tendência a nível internacional, uma vez que a publicação dos instrumentos originais datava da década de 1990. Todavia, acredita-se que esse tipo de produção deva assumir uma curva de crescimento, tanto a nível local, quanto nacional, pois é crescente o número de pesquisadores com interesse no assunto.

Os instrumentos de mensuração fundamentam-se na psicometria, que procura explicar o sentido que têm as respostas dadas pelos sujeitos aos itens de uma escala. Etimologicamente, psicometria representa a teoria e a técnica de medida de processos mentais, pioneiramente aplicados na área da psicologia e da educação ${ }^{(13)}$. Posteriormente, seu uso ampliou-se para outras áreas, dentre elas a saúde ganhou um grande impacto.

Ao se analisar a origem das produções, percebe-se nitidamente a predominância de estudos provenientes da região Sudeste. Essa prevalência pode guardar relação com o fato de a maioria dos cursos de pós-graduação localizar-se nesta região do Brasil, embora, nos últimos anos, a política de incentivo à pesquisa tenha avançando, na tentativa de disseminar a pós-graduação em enfermagem nas demais regiões brasileiras ${ }^{(12)}$.

Em relação às direcionalidades temáticas contempladas nas teses analisadas, observou-se convergência com muitos estudos brasileiros, ao abordarem temas como pré-natal, aleitamento materno e dinâmica familiar de mulheres com câncer de mama. Em contrapartida, revelam-se lacunas em outras temáticas da saúde da mulher, igualmente relevantes, como a anticoncepção, as gestações de risco, o puerpério, o climatério, as doenças sexualmente transmissíveis, dentre outras, fornecendo assim, direcionamento para estudos futuros.

Ressalta-se que, nas teses analisadas, as autoras das versões brasileiras preferiram citar o título dos instrumentos na língua inglesa, não sendo encontradas justificativas para a não tradução destes para a língua portuguesa. No entanto, algumas autoras, ao fazerem menção à versão adaptada transculturalmente para o idioma do Brasil, acrescentaram ao título original a expressão "brazilian version", sendo esta a forma que a maioria dos tradutores de escala prefere para citar o objeto final de suas construções ${ }^{(14-15)}$.

Outro dado que merece destaque é quanto à tradução e adaptação da escala prévia em outros países. Percebeu-se que essa informação foi descrita por duas das três teses analisadas. 
Esse dado deveria constar em todos os estudos desta natureza, pois auxiliaria tanto na compreensão da magnitude do instrumento, como na análise comparativa de sua aplicação, convergindo para uma adaptação transcultural mais acurada e válida.

Em relação ao processo metodológico de tradução e adaptação transcultural, as teses revisadas foram analisadas de acordo com as seis etapas propostas por Beaton et al. ${ }^{(11)}$, em que foi verificado se os critérios estabelecidos pelo autor foram seguidos. Quanto maior o cumprimento, melhor a avaliação quanto à qualidade do trabalho ${ }^{(11)}$.

O processo de adaptação transcultural de uma escala de origem estrangeira requer uma rigorosa metodologia para que se obtenha, no final, uma escala equivalente e não uma mera tradução literal(15). Para isso, a tradução de um instrumento deve seguir passos importantes para garantir essa equivalência entre os dois idiomas envolvidos ${ }^{(14)}$.

Na primeira etapa preconizada por Beaton et al. ${ }^{(11)}$ - Tradução inicial, deverão ser realizadas duas traduções independentes para a língua portuguesa. Uma por um tradutor (T1) que não seja da área de saúde - este não será informado do objetivo da tradução; e outra por um segundo tradutor (T2), que será um profissional de saúde com fluência em inglês este será informado do objetivo da tradução. Ressalta-se que as traduções deverão ser realizadas por brasileiros com fluência em inglês (idioma original da escala) $)^{(11,16)}$.

Nesta etapa, as três teses estão em concordância com referencial metodológico adotado, pois seguiram o número mínimo de tradutores (dois) e a fluência destes no idioma original (inglês).

No entanto, em relação ao critério de que um dos tradutores não deveria ser da área da saúde, houve descumprimento por T1. Quanto à revelação dos objetivos da tradução da escala, este aspecto não foi respeitado por T1 e T3 (não deixaram claro se o fizeram), e foi executado incorretamente por T2 (revelou os objetivos para o tradutor que não era da área da saúde). Destaca-se que para o tradutor pertencente à área da saúde deve ser revelado o objetivo da pesquisa para que o mesmo possa evitar termos técnicos utilizados no campo científico, desconhecidos da população em geral.

Na segunda etapa preconizada por Beaton et al. ${ }^{(11)}$ - Síntese das traduções, a pesquisadora deverá sintetizar os resultados das duas traduções. Esta síntese será cuidadosamente registrada quanto a cada item do instrumento. Após os ajustes entre as duas traduções, o instrumento será utilizado no estágio seguinte ${ }^{(11)}$.

A falta de informação ainda é observada na fase de síntese, onde duas teses, embora a tenham executado, não deixaram claro quem participou dessa fase, fato observado tanto em T2, quanto em T3. Essa última apenas mencionou que a síntese foi realizada por uma "equipe". Esse tipo de conduta dificulta a avaliação dos trabalhos devido à falta de dados importantes para a identificação e compreensão da metodologia.

Na terceira etapa preconizada por Beaton et al. ${ }^{(11)}$ - Tradução de volta à língua de origem (Back-translation), o procedimento adotado consiste em envio do instrumento, para a sua língua oficial, etapa denominada de back-translation, que deve ser executada por dois tradutores sem o conhecimento dos objetivos da back-translation, com o propósito de evitar viés na pesquisa. Após a realização das traduções de volta à língua de origem, os instrumentos serão encaminhados ao próximo estágio.

Porém, os achados dos trabalhos analisados revelam divergência em relação ao cumprimento desses critérios, uma vez que eles foram executados de forma equivocada ou incompleta, demostrando falta de atenção na elaboração desses estudos. Isto corrobora com os achados de outro autor, que observou uma tendência em não conduzir o processo de adaptação transcultural com o rigor metodológico necessário e exigido nesse tipo de trabalho ${ }^{(17)}$.

Na quarta etapa preconizada por Beaton et al.(11) - Revisão por um comitê, no qual todos os instrumentos produzidos até esta fase (as duas traduções, a tradução síntese e as duas versões do back-translation, além da versão original )serão examinados por um comitê de juízes formado por profissionais da área da saúde e conhecimento na temática abordada.

Diante da análise dos critérios estabelecidos pelas teses analisadas quanto à formação do comitê de juízes, percebeu-se que não houve um consenso no perfil deste grupo de experts. Além disso, os referenciais metodológicos disponíveis são breves em sua descrição, não tecendo comentários aprofundados sobre sua composição.

Sintetizando o perfil de juízes com base nos achados das teses analisadas verificou-se: profissionais com título de doutorado e com experiência prática e acadêmica na área em estudo. Entretanto, no sentido de aprimorar o processo de tradução e adaptação, sugere-se como critérios para formação desse comitê: ser profissional de saúde, ser pesquisador doutor, possuir experiência acadêmica e prática na área temática da escala, ter experiência com escalas psicométricas (incluindo utilização, criação, avaliação e validação). Ademais, sugere-se a inclusão de profissionais da área de letras, que poderão auxiliar na adaptação semântica do instrumento. Vale ressaltar, que esta é apenas uma sugestão e que requer aplicação e posterior validação dos pesquisadores interessados no assunto.

$\mathrm{Na}$ quinta etapa preconizada por Beaton et al. ${ }^{(11)}$ - Pré-teste, a versão final do instrumento deverá ser aplicado em uma amostra de 30 a 40 indivíduos, para que seja verificada sua compreensão pela população-alvo. Em relação a esta etapa, todos os critérios foram cumpridos adequadamente por apenas duas das teses analisadas. O cumprimento desta etapa é relevante por oportunizar ajustes advindos de sugestões do público-alvo da escala, verificar a compreensão das questões propostas e servir para o planejamento da aplicação do instrumento final - como tempo gasto no preenchimento, local adequado, forma de abordagem e aceitação da abordagem.

$\mathrm{Na}$ sexta etapa preconizada por Beaton et al. ${ }^{(11)}$ - Submissão aos autores da escala, todos os relatórios e construtos deverão ser enviados aos autores da escala, para verificação do cumprimento de todas as etapas do processo e validade do instrumento. Percebe-se que este é um critério citado apenas por Beaton et al. ${ }^{(11)}$, sendo pouco utilizado nos estudos de tradução e adaptação de escalas. Observou-se no presente estudo que apenas uma tese cumpriu este critério (T3), no entanto, isto fortaleceu seu processo metodológico, contribuindo para a qualidade do seu construto ${ }^{(18)}$.

Após análise dos estudos identificou-se a prevalência da não padronização do processo de tradução e adaptação 
transcultural. Além disso, é perceptível o não detalhamento nas descrições de informações referente ao percurso metodológico seguido, o que dificultou a averiguação acerca da adoção do rigor metodológico exigido para esse tipo de pesquisa, configurando-se como uma limitação do presente estudo.

\section{CONSIDERAÇÕES FINAIS}

O estudo possibilitou identificar os principais focos de produção da enfermagem brasileira em recortes de pesquisa do tipo metodológico na área da saúde sexual e reprodutiva, bem como o cumprimento das etapas requeridas para tal. Os resultados demonstram que ainda é incipiente a produção de teses e dissertações que objetivem traduzir e adaptar escalas na área da saúde sexual e reprodutiva, além da ausência de uniformidade no cumprimento das etapas do percurso metodológico adotado.

Acredita-se que a uniformização e correta execução das etapas de tradução e adaptação transcultural são fundamentais para o alcance de instrumentos de mensuração confiáveis e válidos. Como referencial teórico-metodologico sugerimos Beaton et al. ${ }^{(11)}$, uma vez que ele foi adotado pela maioria dos estudos revisados nesta pesquisa e que apresentaram resultados consistentes.

Espera-se que os achados desta investigação possam contribuir para a execução bem sucedida de futuras investigações. No entanto, considerando que foi utilizado um número pequeno de elementos componentes para o estudo, recomenda-se que as informações aqui fornecidas sejam vistas com parcimônia.

Existe um interesse gonvernamental crescente em otimizar a atenção a saúde da mulher. Diante disso, as produções acadêmicas de instrumentos válidos e confiaveis de mensuração das condições de saude sexual e reprodutiva da mulher, são particularmente relevantes, pois poderão subsidiar boas práticas de enfermagem para esta clientela.

\section{REFERÊNCIAS}

1. Ministério da Saúde. Política nacional de atenção integral à saúde da mulher: princípios e diretrizes. Plano de Ação 2004 - 2007. Brasília, DF: Ministério da Saúde; 2004.

2. Souza KV, Tyrrell MAR. Os fatos \& atos relacionados ao (difícil) exercício dos direitos sexuais e reprodutivos: em recortes, o processo de viver de um grupo de mulheres de classes populares. Texto \& contexto enferm [periódico na internet]. 2007 Mar [acesso 08 jun 2011];16(1):47-54. Disponível em: http://www.scielo.br/scielo.php?pid=S0104$-07072007000100006 \&$ script $=$ sci_arttext

3. Reis CB, Andrade SMO. Representações sociais das enfermeiras sobrea integralidade na assistência à saúde da mulher na rede básica. Ciênc Saúde Coletiva [periódico na internet]. 2008 Fev [acesso em 14 jul 2011];13(1):61-70. Disponível em: http://www.scielo.br/scielo.php?script=sci arttext\&pid $=$ S1413-81232008000100011\&lng $=$ en.

4. Oriá MOB, Ximenes LB. Tradução e adaptação cultural da Breastfeeding Self-Efficacy Scale para o português. Acta Paul Enferm [periódico na internet]. 2010 Abr [acesso em 11 jul 2011]; 23(2):230-38. Disponível em: http://www. scielo.br/scielo.php?script $=$ sci_arttext \&pid $=$ S0103$-21002010000200013 \& \operatorname{lng}=$ en.

5. Whittemore $R$, Knafl $K$. The integrative review: update methodology. J Adv Nurs 2005;52(5): 546-53.

6. Inés Parra D, Arango Bayer GL. Validez y confiabilidad de las escalas de comunicación y coordinación para medir rol interdependiente en enfermería. AV Enferm 2010;28(1):51-62.

7. Galvão CM, Sawada NO, Rossi LA. A prática baseada em evidências: considerações teóricas para sua implementação na enfermagem perioperatória. Rev Latino-Am Enferm 2002;10(5): 690-5.

8. Ganong LH. Integrative reviews of nursing research. Res Nurs Health 1987;10(1):1-11.

9. Beyea $\mathrm{S}, \mathrm{Nicoll} \mathrm{LH}$. Writing an integrative review. AORN J 1998;67(4):877-80.
10. Mendes KDS, Silveira RCCP, Galvão CM. Revisão integrativa: método de pesquisa para a incorporação de evidências na saúde e na enfermagem. Texto \& Contexto Enferm 2008;17(4): 758-64.

11. Beaton DE, Bombardier C, Guillemin F, Ferraz MB. Guidelines for the process of Cross-Cultural Adaptation of Self-Report Measures. Spine 2000;25(24):3186-91.

12. Carvalho GMC, Lima FET, Barbosa IV, Melo EM. Estudos brasileiros sobre nefrologia nas teses e dissertações de enfermagem. Rev Bras Enferm 2010;63(6):1052-1055.

13. Pasquali L. Psicometria. Rev Esc Enferm USP 2009;43( ${ }^{\circ}$. esp.):992-9.

14. Oriá MOB. Tradução, adaptação e validação da Breastfeeding Self-Efficacy Scale: Aplicação em gestantes. Fortaleza. Tese [Doutorado em Enfermagem] - Faculdade de Farmácia, Odontologia e Enfermagem da Universidade Federal do Ceará; 2008.

15. Weissheimer AM. Tradução, adaptação transcultural e validação para uso no Brasil do instrumento Prenatal Psychosocial Profile. Ribeirão Preto. Tese [Doutorado em Enfermagem em Saúde Pública] - Escola de Enfermagem de Ribeirão Preto da USP; 2007.

16. Institute for Work \& Health. Recommendations for the Cross-Cultural Adaptation of the DASH \& QuickDASH Outcome Measures. [S.I.]: Institute for Work \& Health; 2007.

17. Castro RAL, Portela MC, Leão AT. Adaptação transcultural de índices de qualidade de vida relacionada à saúde bucal. Cad Saúde Pública [periódico na internet]. 2007 Out [acesso em 08 jul 2011];23(10):2275-84. Disponível em: http://www.scielo.br/scielo.php?script=sci arttext\&pid $=$ S0102-311X2007001000003\&lng =en.

18. Imada TCML. Adaptação transcultural e validação da Family Dynamics Measure II (FDM II) para familiares de mulheres portadoras de câncer de mama no Brasil. Ribeirão Preto. Tese [Doutorado em Enfermagem em Saúde Pública]- Escola de Enfermagem de Ribeirão Preto da USP; 2008. 